\title{
Transmission of oxygen concentration fluctuations through the diffusive boundary layer overlying aquatic sediments
}

\author{
Hans R $\phi y,{ }^{1}$ Markus Huettel, ${ }^{2}$ and Bo Barker Jørgensen \\ Max Planck Institute for Marine Microbiology, Celsiusstr. 1, D-28359 Bremen, Germany
}

\begin{abstract}
Even though the $\mathrm{O}_{2}$ concentration in the diffusive boundary layer overlying natural aquatic sediments usually varies over time, microprofiles with little or no error bars are abundant in the literature. These temporal concentration fluctuations are not accounted for in the conceptual models used to describe the diffusive boundary layer, and their effects on phenomena investigated through microprofile measurements are unclear. This paper focuses on concentration fluctuations in the diffusive boundary layer above a marine sediment. One microsensor was inserted into a laboratory flume from below and positioned with the sensing tip precisely at the sediment surface. A second microelectrode was deployed from above through the flowing water column and positioned within the diffusive boundary layer directly above the tip of the lower sensor. Time series of the fluctuating $\mathrm{O}_{2}$ concentration at the two points were measured simultaneously with the two sensors and demonstrated a tight coupling of concentration fluctuations across the diffusive boundary layer. A dynamic model accounting only for molecular diffusion plus zero-order $\mathrm{O}_{2}$ consumption within the sediment explained the observed coupling through the diffusive boundary layer and enabled calculation of instantaneous $\mathrm{O}_{2}$ profiles from the top of the true diffusive boundary layer to the depth of $\mathrm{O}_{2}$ penetration. Model results confirmed that concentration fluctuations were linked from the top of the true diffusive boundary layer down to about $0.5 \mathrm{~mm}$ sediment depth. The transient profiles moved back and forth, without losing the general shape derived from the averaged steady state $\mathrm{O}_{2}$ distribution. Apart from this description of the temporal structure of the diffusive boundary layer, the model shows that concentration fluctuations in the layer do not necessarily indicate turbulence within the true diffusive boundary layer. This dynamic description is used to discuss experimental procedures when measuring microprofiles.
\end{abstract}

The diffusive boundary layer (DBL) is the $0.2-1.2-\mathrm{mm}$ thick film of water that coats cohesive sediments through which molecular diffusion is the dominant transport mechanism for solutes (Boudreau and Jørgensen 2001). Viscous forces reduce turbulent mixing in the lowest part of the benthic boundary layer. At a distance of about $1 \mathrm{~mm}$ from the sediment surface, turbulent mixing becomes insignificant for the transport of dissolved substances relative to molecular diffusion.

The lowest part of the DBL exhibits linear concentration profiles and is here referred to as the true DBL (Fig. 1). If the gradient in this layer is extrapolated to the concentration in the water column, we obtain the so-called effective DBL (Jørgensen and Revsbech 1985). The effective DBL represents an idealized layer with a linear gradient throughout its extension.

Although the combined thickness of the DBL and oxic sediment layer can be $<1 \mathrm{~mm}$, highly resolved measurements of oxygen concentration gradients are possible (Fig.

\footnotetext{
${ }^{1}$ Corresponding author (hroey@mpi-bremen.de).

${ }^{2}$ Present address: Florida State University, Department of Oceanography, 900 West Call Street, OSB 517, Tallahassee, FL 323064320 .

\section{Acknowledgments}

The manuscript benefited from comments and criticism of Peter Berg and Eli Precht, as well as Associate Editor Jack Middelburg and two anonymous reviewers. The study was supported by The Danish Research Academy and the Max Planck Society. Niels Peter Revsbech's role as contact person with the Academy, and his interest and support, has been greatly appreciated. Sensors for the study were constructed by Gabriele Eickert and Anja Eggers, and Volker Meyer assisted with electronics and analog technique.
}

1). The diffusive flux $(J)$ through the DBL and across the sediment-water interface can be calculated by Fick's first law of diffusion

$$
J=-D(d C / d z)
$$

where $D$ is the molecular diffusion coefficient for $\mathrm{O}_{2}$ in water, and $d C / d z$ is the vertical concentration gradient.

The mineral grains of the sediment do not allow diffusion of gasses or ions at any appreciable rate. For any cross section of sediment, only the pore space fraction is therefore available to diffusion. Furthermore, the effective diffusion coefficient inside the sediment is lower than in free water because molecules must travel a longer path around the sediment grains. To account for this, Fick's first law must be modified for diffusion within the sediment.

$$
J=-\varphi D_{\mathrm{s}}(d C / d z)
$$

$\varphi$ is the porosity and $D_{\mathrm{s}}$ is the effective diffusion coefficient in the pore water. Several empirical relations between $D_{\mathrm{s}}$ and $\varphi$ exist (e.g., Boudreau 1996). For clay-silt sediment, Iversen and Jørgensen (1993) suggest Eq. 3.

$$
D_{\mathrm{s}}=\frac{D}{1+3(1-\varphi)}
$$

To satisfy conservation of mass, the flux on both sides of the sediment-water interface must be equal. This constraint, combined with a smaller diffusivity in the sediment, forces the slope of the microprofile to become steeper here, forming a slope discontinuity in $\mathrm{O}_{2}$ microprofiles at the sedimentwater interface. This discontinuity is often used to determine the position of the sediment-water interface in measured profiles. By combining Eqs. 1-3, we can derive the relation 


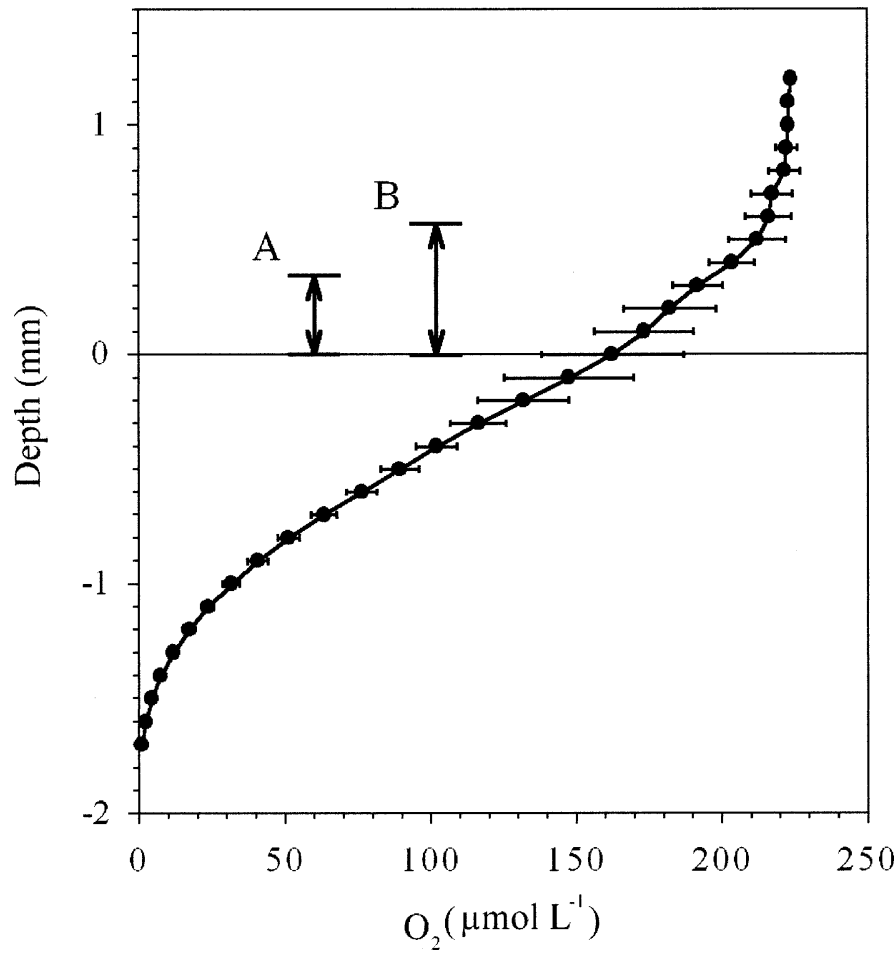

Fig. 1. Time-averaged $\mathrm{O}_{2}$ microprofile through the sedimentwater interface. The strictly linear part from the sediment surface and $0.3 \mathrm{~mm}$ up is the true DBL (A). By extrapolating this linear part of the profile to the $\mathrm{O}_{2}$ concentration of the water column, the effective DBL is found (B). The error bars indicate $2 \times \mathrm{SD}$.

between $\varphi$ and the ratio between the slopes right above and right below the sediment surface.

$$
\varphi=4\left(\frac{d C / d z_{\text {sediment }}}{d C / d z_{\text {water }}}+3\right)^{-1}
$$

Various $\mathrm{O}_{2}$-consuming processes coexist in marine sediments, and each process is controlled by its own kinetics. Thus, the combined kinetics is complex and the amount of $\mathrm{O}_{2}$ consumed per unit of oxic sediment per unit time cannot be correlated to the $\mathrm{O}_{2}$ concentration. Instead, the steady state oxygen microprofiles can most often be reproduced accurately through modeling assuming zero-order kinetics (i.e., no dependence of concentration). Because of different substrate pools, the best agreement between measured and simulated results is often achieved when the profiles are divided into zones of different rates (e.g., Berg et al. 1998). Within each zone, $\mathrm{O}_{2}$ is still consumed at a constant rate. In spite of the apparent zero-order kinetics, the momentary oxygen consumption of the sediment as a whole reacts to a change in the oxygen concentration of the water column. The main mechanism behind this coupling is that higher $\mathrm{O}_{2}$ concentrations at the sediment surface lead to a deeper $\mathrm{O}_{2}$ penetration and, thereby, a larger $\mathrm{O}_{2}$-consuming oxic sediment volume.

Experimental work indicates that concentrations of reactive solutes in the DBL are often variable (Dworak and Wendt 1977; Jørgensen and Des Marais 1990). Measurements with fast-reacting microelectrodes reveal pronounced variability of $\mathrm{O}_{2}$ in the DBL in natural environments and in experimental setups, such as research flumes, that are designed to mimic flow over the seafloor. In more confined systems, like sediment cores, concentration fluctuations are less pronounced or absent. With the concentration fluctuations not accounted for in the conceptual models used to describe the DBL, it is unclear what implications imposed stability could have on phenomena investigated with microprofiles. It has, for example, been proposed that fluctuations in the DBL reflect turbulence within the layer, which would imply that flux calculations based on the linear concentration gradient at the sediment-water interface underestimate the actual diffusive flux (Gundersen and Jørgensen 1990).

This paper analyzes the effect of temporal concentration fluctuations in the DBL in a system in which instability is pronounced. We apply a dynamic model accounting only for molecular diffusion plus zero-order consumption within the sediment, which alone can explain an observed coupling of concentration fluctuations through the DBL. We did not try to identify the hydrodynamic forces initiating the oscillations but focused on a better conceptual understanding of the DBL. We present a dynamic description of the DBL that will allow a case to case judgement of whether the fluctuations must be considered or whether the static view will suffice. This dynamic description is also used to discuss experimental procedures when measuring microprofiles, especially with respect to calculations of the diffusive flux through the DBL.

\section{Methods}

We used a flume with an internal base area of $30 \times 300$ $\mathrm{cm}^{2}$. Flow was driven by recirculating water through an external centrifugal pump. Upstream from the sediment, the water passed through $5 \mathrm{~cm}$ of filter sponge and two $5-\mathrm{cm}-$ long straw collimators to reduce inflow turbulence. One centimeter after the last collimator, a 2-mm-thick wire was placed across the bottom of the flow to start development of a turbulent boundary layer. Downstream from this point, there was $250 \mathrm{~cm}$ of free surface flow over a naturally formed sediment surface. The bulk flow velocity of $\sim 7 \mathrm{~cm}$ $\mathrm{s}^{-1}$ and hydraulic diameter of $8.6 \mathrm{~cm}$ resulted in a Reynolds number of 5,700. Velocity profiles through the $\sim 3$-mm-thick viscous sublayer were measured with a flow microsensor (Unisense). Shear velocity $\left(u_{*}\right)$ after $200 \mathrm{~cm}$ of free flow over the sediment, estimated from the velocity gradient in the viscous sublayer, was $0.15 \mathrm{~cm} \mathrm{~s}^{-1}$.

Sediment was collected from an intertidal mudflat near Dangast, Germany. One square meter of surface sediment, 5 $\mathrm{cm}$ deep, was brought to the laboratory and placed with intact stratification in the flume. North Sea water, diluted to match the pore-water salinity of $25 \%$, was added to the flume, and unidirectional flow was established. The 5-cmhigh water column was exchanged at regular intervals over the following 6 months, after which the fauna composition, water column $\mathrm{O}_{2}$ concentration, diffusive $\mathrm{O}_{2}$ uptake, and visual appearance were constant over a timescale of weeks.

The sediment topography was mostly composed of $0.5-$ 2-mm-high mounds with a density of $5,000 \mathrm{~m}^{-2}$ produced 
by numerous oligochaetes of the Tubifex family. Fecal mounds produced by the polychaete Heteromastus filiformis were equally conspicuous. These mounds were 5-10 $\mathrm{mm}$ high and occurred at $110 \mathrm{~m}^{-2}$. The surface structure was kept dynamic by constant reworking by shrimps, present from the time of sampling. The median grain size was $6.3 \mu \mathrm{m}$. Porosity was $77 \%( \pm 2.5 \% \mathrm{SE}, n=5)$ in the upper $15 \mathrm{~mm}$, determined by drying samples at $60^{\circ} \mathrm{C}$ until at constant weight. Permeability in the top $18 \mathrm{~mm}$ was $1.52 \times 10^{-13} \mathrm{~m}^{2}$ $\left( \pm 0.29 \times 10^{-13} \mathrm{~m}^{2} \mathrm{SE}, n=3\right)$, measured with a constant head of $500 \mathrm{~Pa}$ (Klute and Dirksen 1986). The organic carbon content was $2.9 \%( \pm 0.2 \% \mathrm{SE}, n=10)$ dry weight, determined with a CNS analyzer.

Clark-type $\mathrm{O}_{2}$ microelectrodes (Revsbech 1989) with a tip diameter of $\sim 15 \mu \mathrm{m}$ were used for the experiments. The electrode shafts were made especially long and slender, reaching only $1 \mathrm{~mm}$ in diameter at $50 \mathrm{~mm}$ from the sensing tip. The $90 \%$ response time to a sudden change in $\mathrm{O}_{2}$ concentration was approximately $2 \mathrm{~s}$, and stirring sensitivity was not measurable within the range of flow velocities in the flume. The electrodes were calibrated between the $\mathrm{O}_{2}$ concentrations in the mixed water column, determined by Winkler titration (Strickland and Parson 1972), and the anoxic sediment.
Two sensors were introduced vertically into the DBL from opposite directions $200 \mathrm{~cm}$ downstream of the wire-trip. The lower sensor was introduced through the sediment from below. This was possible through flexible silicone rubber (Dow Conning 734) ports cast into holes in the flume bottom. The two sensors were initially aligned tip to tip while observing the tips through a stereo microscope. Well-defined vertical distances between the tips were then obtained with micromanipulators. Time series of $\mathrm{O}_{2}$ concentrations were recorded simultaneously with both sensors. The signal was sampled through a 1-Hz low-pass filter at $2 \mathrm{~Hz}$, which eliminates interference with electronic noise.

\section{Results}

$\mathrm{O}_{2}$ microprofiles measured from above showed conventional-looking profiles with a $\sim 0.3$-mm-thick true DBL and a $\sim 0.6$-mm-thick effective DBL (Fig. 1). Periodic deviations from bulk water $\mathrm{O}_{2}$ concentration appeared up to $2.5 \mathrm{~mm}$ above the sediment surface, causing time-averaged profiles to curve up to this height. In the sediment, the profiles were parabolas, indicative of molecular diffusion and zero-order kinetics (Rasmussen and Jørgensen 1992). The ratio between the slope of the microprofiles below and above the sedi-

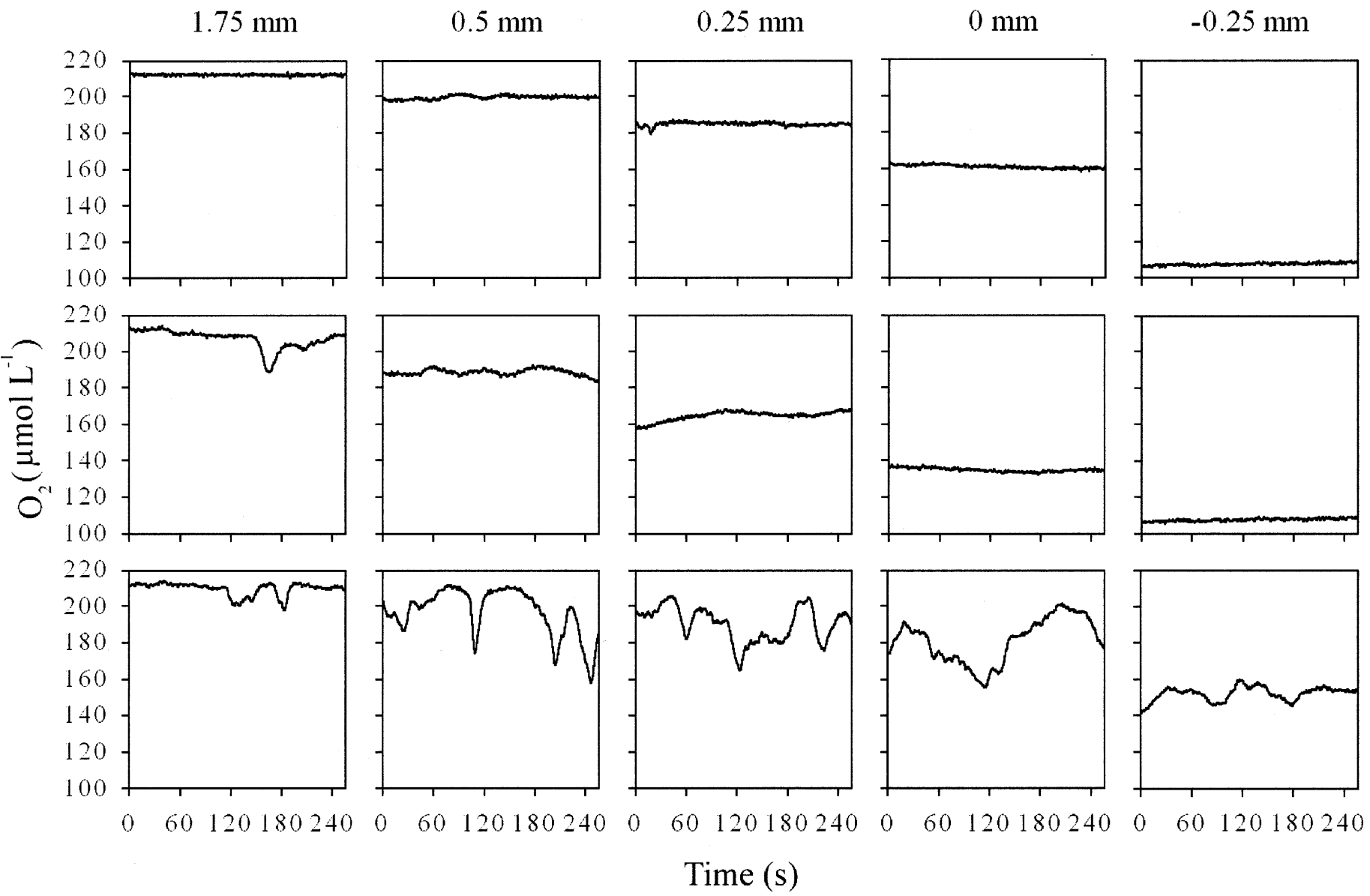

Fig. 2. $\mathrm{O}_{2}$ concentration time series close to the sediment surface 15 (top row), 100 (middle row), and $150 \mathrm{~cm}$ (bottom row) downstream from the leading edge of the sediment. The approximate heights of the sensing tip relative to the sediment surface were 1.75 , 0.5 , 0.25 , 0.0 , and $-0.25 \mathrm{~mm}$. 


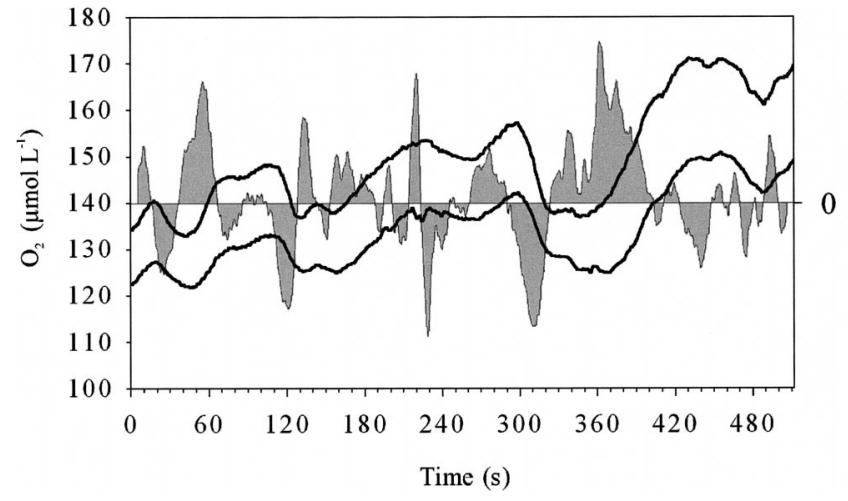

Fig. 3. Example of simultaneous $\mathrm{O}_{2}$ concentration time series measured with two microsensors. The upper line represents a location within the true DBL, whereas the lower line was recorded at the sediment surface from below. The shaded area indicates the change in concentration difference between the two electrode signals $\left(\mu \mathrm{mol} \mathrm{L}^{-1} \mathrm{~s}^{-1}\right)$. Positive values show situations in which the two concentrations are drifting apart, whereas negative values show that the concentrations are approaching each other. The sudden transient drop in $\mathrm{O}_{2}$ concentration at the sediment-water interface at $225 \mathrm{~s}$ was cause by a passing harpacticoid copepod.

ment-water interface was 1.4. According to Eq. 4, this implies a porosity in the surface sediment of 0.9 . When measured from below, the DBL was somewhat thicker, in accordance with earlier observations (Glud et al. 1994; Lorenzen et al. 1995). To avoid disturbances where the microelectrodes had successfully penetrated the silicon ports and sediment, whole profiles were not measured from below.

$\mathrm{O}_{2}$ fluctuations in the DBL were found to vary strongly with the downstream position in the flume. The combination of porous material and straw collimators in the inflow effectively removed all large-scale turbulence, causing $\mathrm{O}_{2}$ distribution in the DBL to be stable close to the flow entrance. Further downstream, the development of a turbulent flow caused strong fluctuations in $\mathrm{O}_{2}$ concentrations in the DBL (Fig. 2).

When one electrode was placed precisely at the sediment surface and the second directly above and within the true DBL, the signals appeared closely coupled (Fig. 3). The vertical distance between the two electrodes while acquiring the data shown in Fig. 3 was $125 \mu \mathrm{m}$ and the average concentration difference was $15.6 \mu \mathrm{mol} \mathrm{L}{ }^{-1}$, which gives a diffusive flux of $22 \mathrm{mmol} \mathrm{O}_{2} \mathrm{~m}^{-2} \mathrm{~d}^{-1}$ according to Eq. 1. Extrapolating the gradient to the bulk water $\mathrm{O}_{2}$ concentration gives a $614-\mu \mathrm{m}$-thick effective DBL. Oxygen penetration into the sediment was $1.7 \mathrm{~mm}$, which agrees well with the penetration predicted from the flux when zero-order kinetics and steady state is assumed (Rasmussen and Jørgensen 1992).

The concentration difference between the two positions $(\Delta C)$ was not constant but was coupled to the concentration fluctuations. The shaded areas in Fig. 3 show the rate at which the concentration difference changed $(d \Delta C / d t)$. Positive values appear where the signals drift apart, and negative values appear when the signals near one another. Note that decreasing $\mathrm{O}_{2}$ concentration is typically accompanied by decreasing concentration difference (negative $d \Delta C / d t$ ) and vice

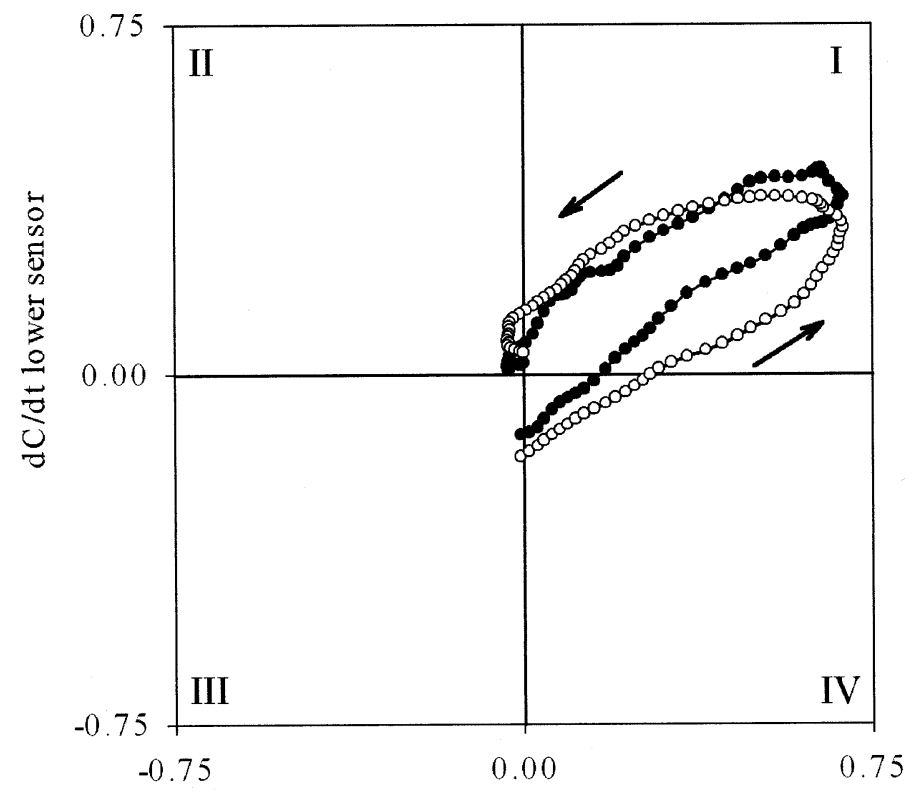

$\mathrm{dC} / \mathrm{dt}$ upper sensor

Fig. 4. Short sequence of change in $\mathrm{O}_{2}$ concentration $(d C / d t)$ at the sediment surface as a function of the change $125 \mu \mathrm{m}$ above the sediment-water interface. The change was calculated from the concentration measurements seen from 40 to $83 \mathrm{~s}$ in Fig. 3. The filled symbols represent data measured with two sensors. Open symbols represent the same measured values of the upper sensor, but the data of the lower sensor were replaced by simulated results.

versa, so that the fluctuations are slightly dampened at the lowest position. Note also that the response of the lower sensor is slightly delayed relative to the signal of the upper sensor. In Fig. 3, this can be seen best around peaks of the upper sensor. This delay is, however, seen more clearly when the concentration change in time $(d C / d t)$ at the sediment surface is plotted as a function of the rate of change further up in the DBL (Fig. 4, filled symbols). The coupling of the two signals causes the plotted values to move between simultaneously increasing concentrations in quadrant I and simultaneously decreasing concentrations in quadrant III. However, the delay at the sediment-water interface causes the rate at the lower sensor to increase for a short time after the rate has started decreasing at the upper sensor. As a result, the plotted values describe a counterclockwise semicircle. How wide the circle is opened is a sensitive measure of the delay of the response on the lower sensor.

The delayed and dampened signal at the sediment-water interface shows that concentration fluctuations must be controlled from above. If the concept of a "true DBL" as a zone of exclusively diffusive transport is valid, the coupling of fluctuations across the DBL must be via molecular diffusion, too. By applying a dynamic model accounting only for molecular diffusion plus zero-order consumption within the sediment, we can identify to what extent the observed coupling of the concentration fluctuations can be explained by diffusion rather than by turbulence.

The applied dynamic model is based on a vertical array of control volumes, each with a grid point in the center. The 


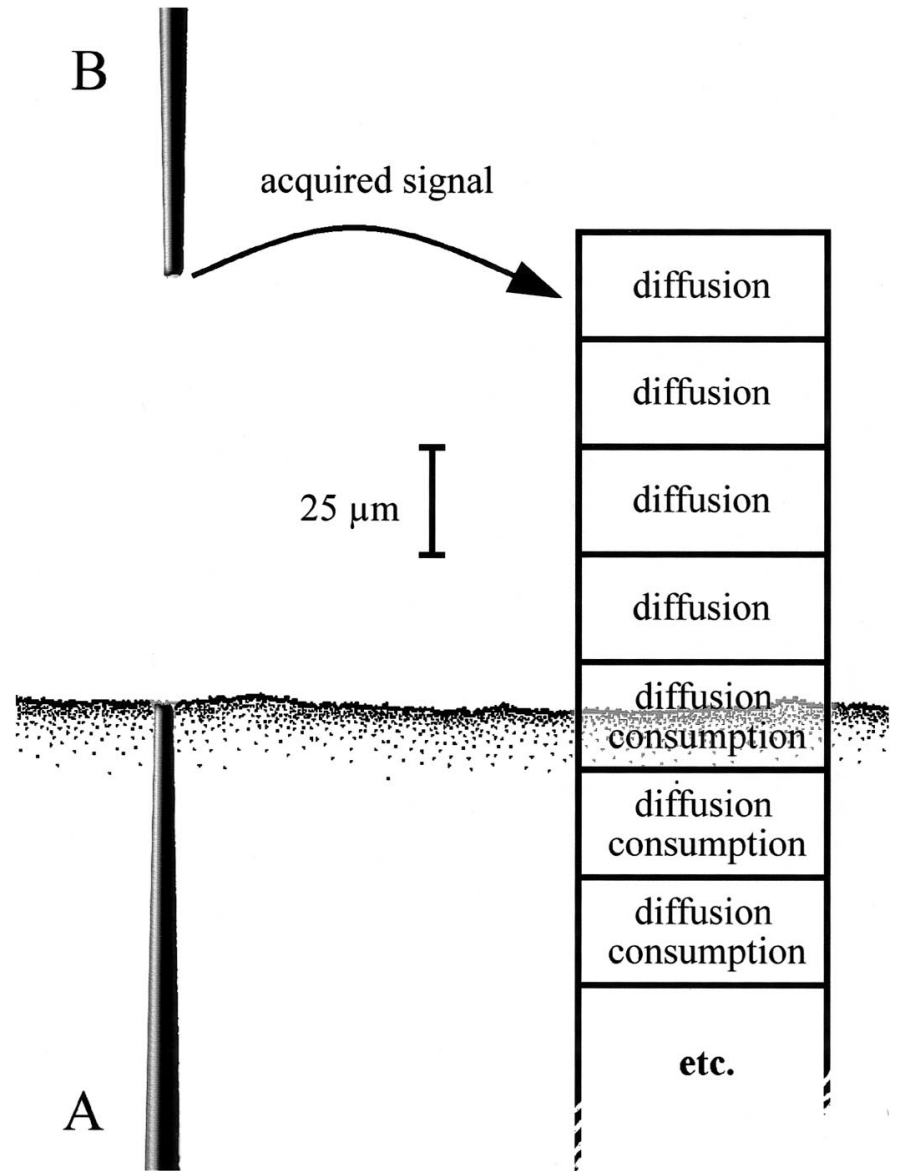

Fig. 5. Experimental setup and model structure. The two sensors (A, B) were introduced from opposite directions and aligned horizontally tip to tip. The lower sensor was fixed with the tip exactly at the sediment-water interface, and the upper sensor was placed above in the true DBL. The top of the modeled zone is located at the height of the upper sensor, and the concentrations measured by this sensor were used to force the model.

control volumes represent $25-\mu \mathrm{m}$-thick layers of water or sediment (Fig. 5). The center of the top control volume represents the position of the upper sensor, and the array extends downward across the sediment-water interface to well below the expected penetration depth of $\mathrm{O}_{2}$. Between the control volumes, $\mathrm{O}_{2}$ is transported by molecular diffusion according to Eq. 1 or 2. Fluxes between control volumes were calculated from the known concentrations at the beginning of each time step and were assumed to be constant throughout the time step. Consumption in the sediment cells was independent of depth and concentration, provided enough $\mathrm{O}_{2}$ was present in the control volume. This requirement was only expressed in the last volume containing $\mathrm{O}_{2}$. The model was extended so far downward that zero oxygen was always reached. The cell at the sediment-water interface was modeled as a half-sediment, half-water column. This modeling approach is an explicit numerical solution to the mass conservation equation $\varphi \partial C / \partial t=-\partial J / \partial z-\varphi R$, where $R$ is the $\mathrm{O}_{2}$ consumption per unit volume of pore water (e.g., Rysgaard and Berg 1996; Boudreau 1997).

Model simulations giving the $\mathrm{O}_{2}$ concentration for the
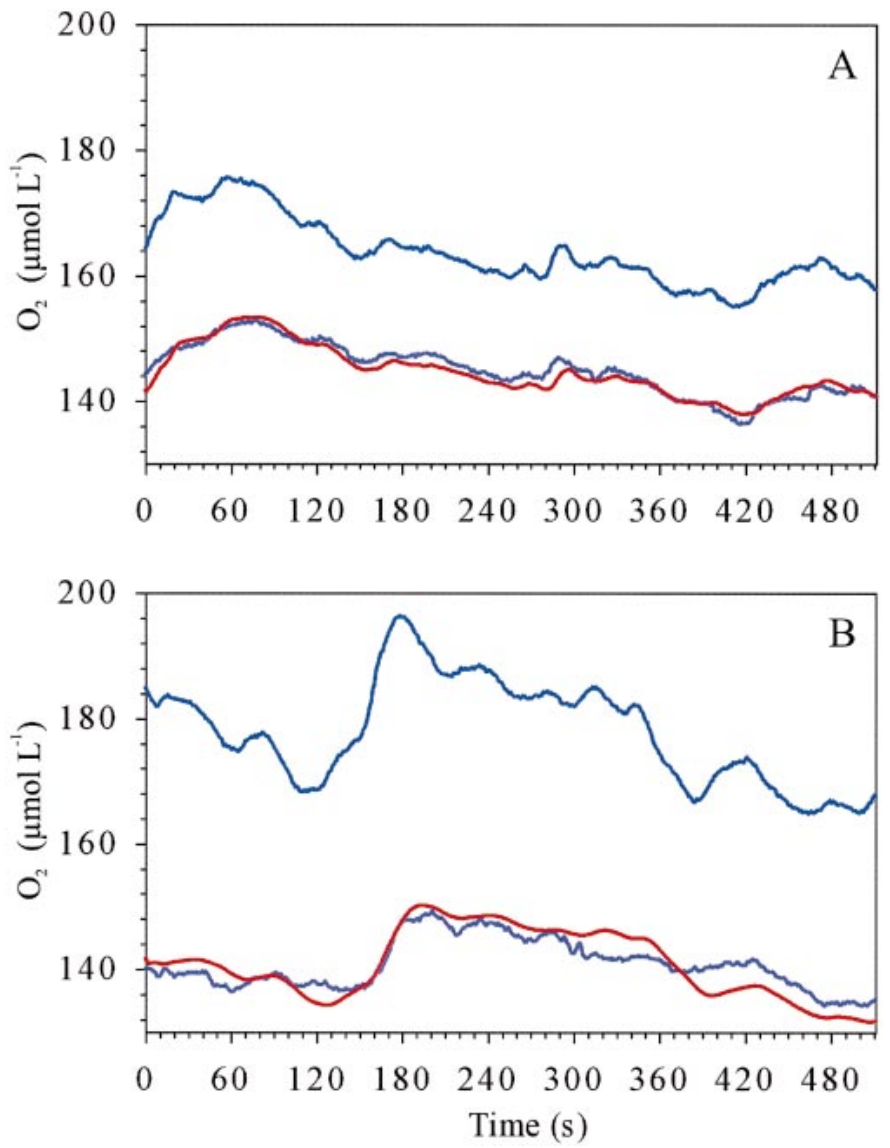

Fig. 6. Comparison of modeled and measured $\mathrm{O}_{2}$ concentrations at the sediment-water interface. The upper blue line was measured within in the DBL and the lower blue line precisely at the sediment surface. The red line represents the simulated concentration at the sediment surface after using the values measured in the DBL as input to the model. The distances between the sensors were $100 \mu \mathrm{m}$ (A) and $200 \mu \mathrm{m}(\mathrm{B})$.

control volumes over time were performed with 0.125 -s time steps by imposing the measured fluctuating concentration in the top control volume. To match the temporal resolution between measured concentrations and time steps used in the model, the measured time series were interpolated accordingly. The maximum divergence when model simulations were reproduced with 10 times higher temporal resolution was $<0.01 \%$ of the water column concentration.

All input parameters to the model are available as physical constants or from interpretation of the microelectrode data: $D$ at appropriate temperature and salinity was calculated following Li and Gregory (1974). Porosity was calculated from the slope discontinuity as discussed above. $D_{\mathrm{s}}$ was calculated from Eq. 3. The average concentration difference between the two sensors, together with the distance between the sensors and $D$, provides the diffusive flux according to Eq. 1 . The depth-independent consumption rate of $\mathrm{O}_{2}$ per unit volume of pore water $(R)$ was found by dividing the flux by $\mathrm{O}_{2}$ penetration depth and porosity. The actual parameter values used in model simulations were: $\varphi=0.9, D=2.02 \times 10^{-5}$ 


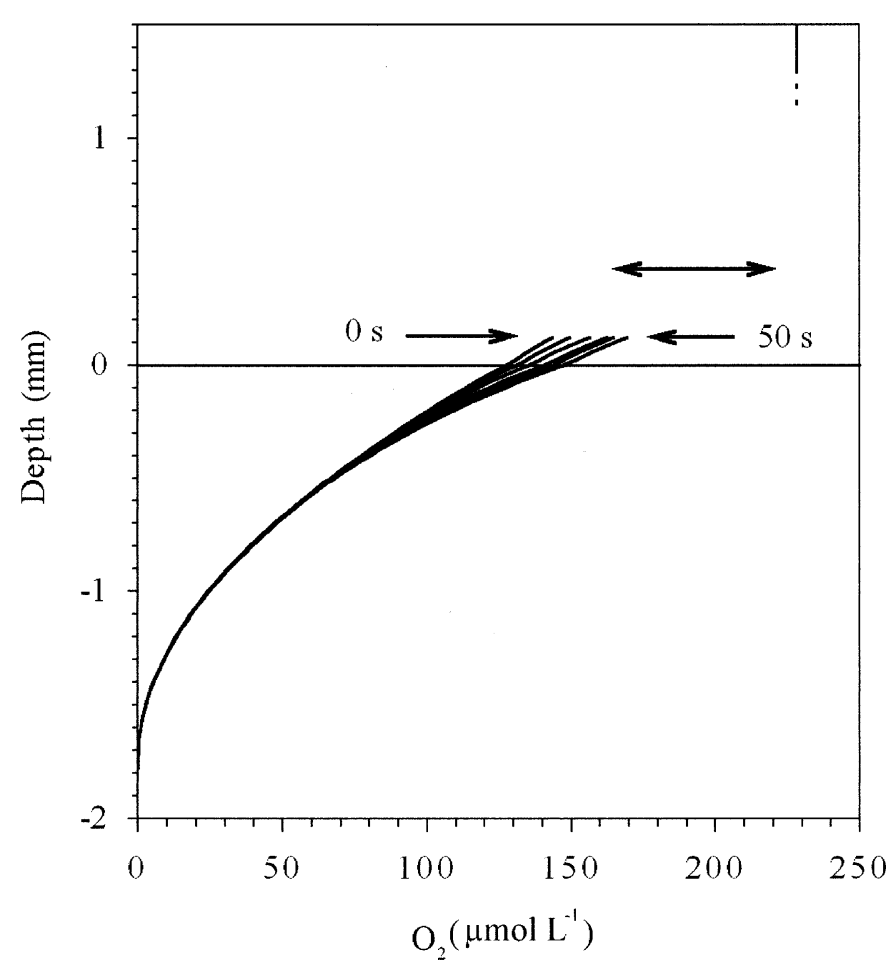

Fig. 7. Example of simulated instantaneous $\mathrm{O}_{2}$ profiles over 50 $s$ of increasing $\mathrm{O}_{2}$ concentrations in the DBL. The concentration at the top of the profile was measured, and the simulated concentration at the sediment surface was verified with the lower sensor as in Fig. 6. The time between the profiles is $10 \mathrm{~s}$. This interval with pronounced fluctuation corresponds to the time from 374 to $424 \mathrm{~s}$ in Fig. 3. Most other 50-s intervals showed a smaller amplitude and more than one fluctuation. The profile in the figure can be divided into four sections: Deeper than $\sim 0.5 \mathrm{~mm}$ into the sediment, the $\mathrm{O}_{2}$ concentration is stable. Above this point, the profile shifts back and forth while retaining the general shape of a steady state profile. The double-headed arrow indicates the range of these fluctuations. From $0.3 \mathrm{~mm}$ above the sediment and upward, turbulence becomes a significant transport mechanism, and the model cannot reveal the momentary $\mathrm{O}_{2}$ distribution. The last region is the part of the profile more than $1 \mathrm{~mm}$ above the sediment-water interface, where efficient mixing assures practically constant $\mathrm{O}_{2}$ concentration.

$\mathrm{cm}^{2} \mathrm{~s}^{-1}, D_{\mathrm{s}}=1.55 \times 10^{-5} \mathrm{~cm}^{2} \mathrm{~s}^{-1}$, and $R=1.49 \times 10^{-10}$ mol cm ${ }^{-3} \mathrm{~s}^{-1}$.

When forced with a constant concentration in the top control volume and run until steady state, the model gives a linear gradient above the sediment-water interface, a slope discontinuity at the interface, and a parabolic decrease to zero $\mathrm{O}_{2}$ concentration at some sediment depth. The same result can be derived analytically (Rasmussen and Jørgensen 1992), and the two solutions agree within $0.01 \%$ of the water column concentration. By imposing the fluctuating time series of $\mathrm{O}_{2}$ in the top control volume, time series for any depth in the sediment can then be calculated (Fig. 6) together with entire instantaneous $\mathrm{O}_{2}$ profiles (Fig. 7). Because the history of the $\mathrm{O}_{2}$ concentration was not known before the period covered by measurements, the model was initialized with a steady state profile derived from the average $\mathrm{O}_{2}$ concentration in the top cell. Model output for the first $\sim 60$ s of simulated time should therefore be disregarded. Apart from this initial phase, a close match between modeled and measured $\mathrm{O}_{2}$ concentration at the sediment-water interface was found (Fig. 6). As shown in Fig. 4, the magnitude and delay in the rate of concentration change in time also was accurately simulated.

\section{Discussion}

Although the sequentially measured time series in Fig. 2 give a chaotic impression of the gradient in the DBL, the modeled instantaneous profiles in Fig. 7 show a much more orderly system. During this continued concentration increase over $50 \mathrm{~s}$ (from time $374 \mathrm{~s}$ to time $424 \mathrm{~s}$ in Fig. 3), the entire $\mathrm{O}_{2}$ profile bent toward higher concentrations. When observed over longer time, the profile appears to be gently moving back and forth without any visible changes of the overall profile shape. This indicates that the error bars shown in Fig. 1, at least for the linear part of the DBL and downward, represent such coordinated concentration fluctuations.

The decreasing amplitude of the fluctuations with depth is in part due to the decreasing $\mathrm{O}_{2}$ concentration but mostly is caused by the strong influence of distance on diffusive transport. This can be demonstrated by modeling the propagation of a $20-\mu \mathrm{mol} \mathrm{L} \mathrm{L}^{-1}$ reduction in $\mathrm{O}_{2}$ concentration imposed $300 \mu \mathrm{m}$ above the sediment surface. With the model parameters described above, concentrations at the sedimentwater interface reached halfway to the new steady state after $33 \mathrm{~s}$. After these $33 \mathrm{~s}$, a point $300 \mu \mathrm{m}$ below the sedimentwater interface had only reached $13 \%$ of the change to its new steady state, and the adjustment $1 \mathrm{~mm}$ into the sediment is insignificant. The $120 \mathrm{~s}$ needed to bring about $50 \%$ of the full change $300 \mu \mathrm{m}$ into the sediment would barely cause a $1-\mu \mathrm{mol} \mathrm{L}-1$ change at $1 \mathrm{~mm}$ depth. Thus, with a timescale of the fluctuations in the range of $20-120 \mathrm{~s}$, the sediment at $300 \mu \mathrm{m}$ depth experiences fluctuations from the DBL that is significantly dampened, and the sediment $1 \mathrm{~mm}$ from the surface is not affected. To get the entire 1.7-mm-deep profile to within $1 \mu \mathrm{mol} \mathrm{L} \mathrm{L}^{-1}$ of the new steady state following a $20-\mu \mathrm{mol} \mathrm{L}{ }^{-1}$ change at the top of the DBL requires about $10 \mathrm{~min}$.

The concentration fluctuations generate temporal heterogeneity around the sediment-water interface with a period of $\sim 20-120$ s. Because the single points in microprofile measurements are usually integrated over just a few seconds, the result is often irregularly shaped profiles. Averaging over several fluctuations is an obvious solution to this problem, but with a period of up to several minutes, this might require impractically long measuring times for profiles typically consisting of 25-100 data points. An alternative is to measure fast, thus trying to outrun the fluctuations. This approach can give sound-looking profiles, even under fluctuating conditions, as shown in Fig. 2; yet, the method should be avoided because it clearly yields non-steady state profiles. It can be assumed that the fluctuations constitute a roughly constant fraction of the concentration difference between the sediment surface and the water column. Consequently, the fluctuations contribute constant relative noise to flux calculations from DBL profiles. It is therefore a good strategy to integrate $\mathrm{O}_{2}$ measurements in the DBL over sev- 
eral minutes, even though the small fluctuations in a shallow gradient appear to be negligible. Long integration time, especially, makes sense in situ, where the constant temperature and isolation from electric and magnetic noise make differential measurements of even small changes highly accurate.

In laboratory situations and when specific process studies in the sediment are of interest, the most practical solution is to avoid hydrodynamic conditions that cause fluctuations. This can be done by avoiding well-developed turbulent flows by, for example, measuring in sediment cores and stirring the shallow water column only by a gentle air jet. Small flow cells perform equally well, given that unstable turbulence in the inflow is dissipated. However, these approaches require that the flow velocity is adjusted to provide a realistic thickness of the DBL.

If the objective when acquiring the microprofiles goes beyond flux calculations, the fluctuations should not be considered simple measurement noise. The fluctuations are a natural property of the DBL because the turbulence controlling the DBL's upper limit is not homogeneous in time. So whereas the error bars in Fig. 1 are still the best description in the nonlinear part of the DBL, the profile in the linear part and further down can be much better understood from the representation in Fig. 7. The significance of presence or absence of concentration fluctuations should be considered from case to case. Generally, the major influence of oxygen on aspects like kinetics and chemotaxis occurs at concentrations $<10 \mu \mathrm{mol} \mathrm{L}{ }^{-1}$. To have these low concentrations influenced by the fluctuations require such a shallow $\mathrm{O}_{2}$ penetration that a significant effect is not likely except in diffusion-limited communities like sulfureta. When dealing with diffusion-limited systems, considerations about concentration-driven phenomena, such as the ability of Thiovulum majus to swim along the $10-\mu$ mol $\mathrm{L}^{-1}$ isopleth (Thar and Fenchel 2001), should take into account that the gradient in the DBL under at least some conditions is migrating up and down.

We have traced the propagation of the concentration fluctuations from a given point in the true DBL downward. Although the origin of the fluctuations was not the objective of this study, it is interesting to compare the timescale of the observed fluctuations with temporal structures in the turbulent flow. Turbulence is not strictly random, but to some extent it is organized in large-scale structures, known as coherent motions. Dade et al. (2001) gives the timescale to be $10^{2} \nu / u_{*}^{2}$ when observed from a fixed point. In our case, this would imply a timescale of $46 \mathrm{~s}\left(\nu=1.04 \times 10^{-2} \mathrm{~cm}^{2} \mathrm{~s}^{-1}\right.$, $u_{*}=0.15 \mathrm{~cm} \mathrm{~s}^{-1}$ ). So, whereas the timescales of the $\mathrm{O}_{2}$ fluctuations measured in the DBL are far too slow to be explained by the effect of single eddies, the frequencies lie within the range that can be explained by coherent motions.

\section{References}

Berg, P., Risgaard-Petersen, N. Rysgaard, S. 1998. Interpretation of measured concentration profiles in sediment pore water. Limnol. Oceanogr. 43: 1500-1510.
BoudREAU, B. P. 1996. The diffusive tortuosity of fine-grained unlithified sediments. Geochim. Cosmochim. Acta. 60: 31393142 .

- 1997. Diagenetic models and their implementation. Springer-Verlag.

, AND B. B. JøRGENSEN. 2001. The Benthic Boundary Layer: Transport processes and biogeochemistry. Oxford University Press.

Dade, B. W., A. J. Hogg And B. P. Boudreau. 2001. Physics of flow above the sediment-water interface, p. 4-43. In B. P. Boudreau and B. B. Jørgenesen [eds.], The benthic boundary layer: Transport processes and biogeochemistry. Oxford University Press.

DworaK, R. AND H. WendT. 1977. Stochastic fluctuations of mass transport through turbulent boundary layers. Berichte der Bunsen-Gesellschaft Phyk. Chem. 81: 864-869.

Glud, R. N., J. K. Gundersen, N. P. Revsbech and B. B. JøRGENSEN. 1994. Effects on the benthic diffusive boundary layer imposed by microelectrodes. Limnol. Oceanogr. 39: 462467.

Gundersen, J. K. AND B. B. JøRGENSEN. 1990. Microstructure of diffusive boundary layers and the oxygen uptake of the sea floor. Nature 345: 604-607.

IVERSEN, N. AND B. B. JøRGENSEN. 1993. Diffusion coefficients of sulfate and methane in marine sediments influence of porosity. Geochim. Cosmochim. Acta. 57: 571-578.

Jørgensen, B. B., And D. J. Des Marais. 1990. The diffusive boundary layer of sediments: Oxygen microgradients over a microbial mat. Limnol. Oceanogr. 35: 1343-1355.

— the oxygen uptake of sediments and detritus. Limnol. Oceanogr. 30: 111-122.

Klute, A. AND C. DiRKSEn. 1986. Hydraulic conductivity and diffusivity: laboratory methods, p. 687-734. In A. Klute [ed.], Methods of soil analysis-part 1-physical and mineralogical methods. American Society of Agronomy.

LI, Y. H. AND S. GRegory. 1974. Diffusion of ions in sea-water and in deep-sea sediments. Geochim. Cosmochim. Acta. 38: 703-714.

Lorenzen, J., R. N. Glud AND N. P. Revsbech. 1995. Impact of microsensor-caused changes in diffusive boundary layer thickness on $\mathrm{O}_{2}$ profiles and photosynthetic rates in benthic communities of microorganisms. Mar. Ecol. Prog. Ser. 19: 237241.

Rasmussen, H. AND B. B. JøRGensen. 1992. Microelectrode studies of seasonal oxygen uptake in a coastal sediment: role of molecular diffusion. Mar. Ecol. Prog. Ser. 81: 289-303.

RevsbeCH, N. P. 1989. An oxygen microsensor with a guard cathode. Limnol. Oceanogr. 34: 474-478.

RYSGAARD, S. AND P. BERG. 1996. Mineralization in a northeastern Greenland sediment: Mathematical modelling, measured sediment pore water profiles and actual activities. Aquat. Microb. Ecol. 11: 297-305.

Strickland, J. D. AND T. R. PARSON. 1972. A practical handbook of seawater analysis. Pergamon Press.

Thar, R. AND T. Fenchel. 2001. True chemotaxis in oxygen gradients of the sulfur-oxidizing bacterium Thiovulum majus. Appl. Environ. Microbiol. 67: 3299-3303.

Received: 14 August 2003 Accepted: 5 January 2004 Amended: 26 January 2004 